\title{
Review Study of the Impulsiveness Dimension of the Dimensional Clinical Personality Inventory *
}

\section{Estudio de revisión de la dimensión Impulsividad del Inventario Dimensional Clínico de la Personalidad}

\author{
Lucas de Francisco Carvalho \\ Universidade São Francisco, Brasil \\ ORCID: http://orcid.org/0000-0002-3274-9724
}

Received: 04 December 2014 | Accepted: 07 June 2017

\begin{tabular}{l}
\hline a Correspondence author. \\
lucas@labape.com.br \\
How to cite: Carvalho, L. de F. (2018). \\
Review study of the Impulsiveness dimension of \\
the Dimensional Clinical Personality Inventory. \\
Universitas Psychologica, 17(1), 1-11. https:// \\
doi.org/10.1114 4/Javeriana.upsy17-1.rsid
\end{tabular}
doi.org/10.1114 4/Javeriana.upsy17-1.rsid

\begin{abstract}
The present study aimed to review the Impulsiveness dimension from Dimensional Clinical Personality Inventory (IDCP) as well as to verify its psychometric properties in a non-clinical sample. The procedures were performed in 2-stages. Step 1 was directed at the development of new items and Step 2 intended for testing the psychometric properties of the revised version. As a result of the first step, we selected a set of 38 items. In the second step, the items were tested in a sample of 225 subjects (70.1\%females), aged 18 to 66 years $(\mathrm{M}=26.2, \mathrm{SD}=8.1)$, mostly undergraduate students (58.9\%). All subjects answered the IDCP, and the Brazilian versions of both, the Revised NEO Personality Inventory (NEO-PI-R) and the Personality Inventory for DSM-5 (PID-5). As result, we obtained a set of 18 items in three interpretable factors, Inconsequence, Risk Taking, and Deceitfulness, with internal consistency coefficients (Cronbach's $\alpha$ ) of .89 for the total score. The correlations of the Impulsiveness factors with NEO-PI-R and PID-5 revealed consistent and expected relations. The data reveal the adequacy of the revised dimension of IDCP.

Keywords

impulsivity; personality traits; inconsequence; personality disorders; DSM-5.
\end{abstract}

\section{RESUMEN}

El presente estudio tuvo como objetivo revisar la dimensión Impulsividad del Inventario Dimensional Clínico de la Personalidad (IDCP), así como para comprobar las propiedades psicométricas en una muestra no clínica. El procedimiento se realizó en dos etapas: paso 1, dirigido al desarrollo de nuevos productos y el paso 2 destinado a probar las propiedades psicométricas de la versión revisada. Como resultado de la primera etapa, se seleccionó un conjunto de 38 artículos. En el segundo paso, los elementos fueron probados en una muestra de 225 sujetos $(70.1 \%$ mujeres), con edades comprendidas entre 18 y 66 años $(M=26.2, D E=$ 8.1 ), en su mayoría estudiantes universitarios (58.9\%). Todos los sujetos respondieron el IDCP y las versiones brasileñas de ambos: el Inventario Revisado NEO Personality (NEO-PI-R) y el Inventario de Personalidad para el DSM-5 (PID-5). Como resultado, se obtuvo un conjunto de 18 artículos en tres factores interpretables, Inconsecuencia, Asunción de riesgos y Falsedad, con coeficientes de consistencia interna ( $\alpha$ de Cronbach) de 0.89 para la puntuación total. Las correlaciones de los factores de Impulsividad con NEO-PI-R y PID-5 revelaron relaciones 
consistentes y esperadas. Los datos ponen de manifiesto la idoneidad de la nueva dimensión Impulsividad del IDCP.

Palabras clave

impulsividad; rasgos de personalidade; inconsecuencia; trastornos de la personalidade; DSM-5.

It is estimated that between $2 \%$ and $9 \%$ of the general population have a personality disorder (Huang et al., 2009; Lenzenweger, Lane, Loranger, \& Kessler 2007). In Brazil, the number of instruments to evaluate typical pathological traits of these disorders is scarce (Carvalho, Bartholomeu, \& Silva, 2010). Based on that, Carvalho and Primi (2015) developed the Dimensional Clinical Personality Inventory (IDCP) based on criteria Diagnostic and Statistical Manual of Mental Disorders axis II and characteristics presented in Millon's theory (Millon \& Grossman, 2007a; 2007b; Millon, Grossman, \& Tringone, 2010). Despite the adequacy in its psychometric properties (Carvalho, Oliveira Filho, Pessotto, \& Bortolotti, 2014; Carvalho \& Primi, 2015, 2016; Carvalho, Primi, \& Stone, 2014), revisions in IDCP's dimensions are being made, considering the expansion in the constructs coverage and the build-up of psychometric evidence using the instrument. The present study focuses on one of IDCP dimensions, Impulsiveness, related to characteristics such as recklessness, imprudent, and risk taking behaviour.

Impulsiveness is defined as a propensity to act without the apparent capacity to adapt behaviour to contextual demands and is prominent in many psychiatric disorders (Moeller, Barratt, Dougherty, Schmitz, \& Swann, 2001). In relation to personality disorders (PD), both antisocial and borderline are characterized by poor impulse, i.e., impulsiveness, and also aggressiveness (American Psychiatric Association [APA], Diagnostic and Statistical Manual of Mental Disorders [DSM-5], 2013; Guy, Poythress, Douglas, Skeem, \& Edens, 2008; McCloskey et al., 2009; Ohayon, 2009; Swann, Lijffijt, Lane, Steinberg, \& Moeller, 2009).

Antisocial PD is defined by DSM-5 (APA, 2013, p. 659) as "a pervasive pattern of disregard for and violation of the rights of others", including in 3 and 5 criteria, impulsiveness and reckless. In the DSM-5 section 3, impulsiveness underlies some antisocial characteristics such as deceitfulness, irresponsibility, manipulativeness, and risk taking. According to literature (Anderson, Sellbom, Wygant, Salekin, \& Krueger, 2014; Coid \& Ulrich, 2010), the antisocial PD, as described in DSM-IV-TR, refers mainly to behavioral aspects (e.g., aggressiveness). Therefore, considering the DSM-5 (APA, 2013), section 3 and the Personality Inventory for DSM-5 facets ([PID -5]; Krueger, Derringer, Markon, Watson, \& Skodol, 2012) extends the coverage of knowledge related to the antisocial PD, for instance, taking into account the person's inner world (Poythress \& Hall, 2011). Besides, DSM-5 (p. 663) also defines borderline PD as "a pervasive pattern of instability of interpersonal relationships, selfimage, and affects, and marked impulsivity," where impulsiveness is clearly established in the fourth criterion. In the case of borderline, impulsivity is clearly mentioned in DSM-5 section 3, as well risk taking.

As it can be viewed, impulsivity is considered an important personality trait when assessing pathological personality continuum. In Brazil, one of the tests developed for pathological personality traits having a dimension to impulsivity assessment is the IDCP, developed (Carvalho \& Primi, 2015) to be used with both, non-clinical and clinical samples, composed by 163 items distributed in 12 dimensions (Dependency, Aggressiveness, Mood Instability, Eccentricity, Attention Seeking, Distrust, Grandiosity, Isolation, Criticism Avoidance, Selfsacrifice, Conscientiousness, and Impulsiveness). Its last dimension, Impulsiveness is represented by six items concerning violent behaviour, recklessness, and intense experiences. As pointed by Carvalho \& Primi (2015), Impulsiveness dimension is priority related to Antissocial PD characteristcs, but also to Borderline PD.

Abela (2013) conducted a study in which, among other results, patients diagnosed with antisocial PD $(\mathrm{N}=3)$ presented very high scores in Impulsiveness dimension; still, data with 
borderline PD $(\mathrm{N}=57)$ showed scores somewhat high in the same dimensions. The results suggests that the Impulsiveness dimension is priority related to DSM-IV-R antisocial PD typical criteria (e.g., recklessness and aggressiveness) and impulsivity criteria of borderline PD in the same manual. Considering the expansion on the impulsivity understanding (e.g., DSM-5 section 3; APA, 2013) and the need to increase of construct representation and number of items of IDCP's Impulsiveness, the present study aimed to review this dimension from IDCP as well as to verify its psychometric properties in a nonclinical sample. The procedures were based on previous studies reviewing IDCP's dimension (Carvalho, de Souza, \& Primi, 2014; Carvalho, Sette, Capitão, \& Primi, 2014), in 2-stages. Step 1 was directed at the development of new items and Step 2 intended for testing the psychometric properties of the revised version.

\section{Method}

The review was performed in two stages; the first concerning the development of new items development and Step 2 was intended to verify psychometric properties of the revised version of the dimension.

\section{Step 1}

\section{Procedures}

For the development of the new Impulsiveness items, we verified complementary literature considered as relevant, focused on personality pathological traits, replicating previously procedures (Carvalho, de Souza et al., 2014; Carvalho, Sette et al., 2014). We consulted Section 3 of the 5 th edition DSM-5 (APA, 2013), facets of the Personality Inventory for DSM-5 ([PID-5]; Krueger et al., 2012), dimensions definition of the Shedler-Westen Assessment Procedure ([SWAP-200]; Shedler \& Westen, 2004), and model of Clark (1990) that supports the Schedule for Nonadaptive Personality (SNAP).

The literature was analyzed and independently selected by two judges, the author and a Ph.D. in psychology that works in the personalityassessment field, who sought to select the constructs and characteristics considered as relevant to impulsivity and to antisocial (priority) and borderline (minor) PD. The original sentences (i.e., English) were included in a spreadsheet, which was followed by independent translation and consensus between the author and the Ph.D.

Based on the selected sentences, new items were developed. For each sentence, four to eight items were generated. After the creation of items, a pre-selection was made, trying to select the items with most adequate content. The final composite of items to be tested was generated by consensus between the author and the Ph.D., focusing on representativeness of the characteristics, pathological levels of the construct, clarity in writing, and no redundancy of content.

Step 2

\section{Participants}

225 participants, aged 18 to $66(\mathrm{M}=26.2$, $\mathrm{SD}=8.1), 162$ females $(70.1 \%)$, and the majority were undergraduate students (58.9\%), accessed by convenience. Participants with a history of psychiatric/psychological treatment were identified, of which 68 reported having undergone psychotherapeutic process, 12 have made psychiatric treatment, and 11 reported use of psychotropic medication.

\section{Instruments}

For this study, three instruments were applied, the Dimensional Clinical Personality Inventory ([IDCP]; Carvalho \& Primi (2015), the Brazilian version of the NEO Personality Inventory Revised ([NEO-PI-R]; Costa \& McCrae, 2009), 
and the Brazilian version of the Personality Inventory for DSM-5 ([PID-5]; Krueger et al., 2012).

The IDCP is an instrument developed for the assessment of pathological personality traits based on the theory of Millon (Millon \& Grossman, 2007a, 2007b) and diagnostic criteria of axis II of the Diagnostic and Statistical Manual of Mental Disorders ([DSM-IV-TR]; APA, 2003). Originally the instrument comprises 163 items on a Likert 4-point scale, where 1 stands for "has nothing to do with me" and four for "everything to do with me", with an average time to complete of 25 minutes. The items cover the IDCP 12 personality dimensions, namely, Dependency, Aggressiveness, Mood Instability, Eccentricity, Attention Seeking, Distrust, Grandiosity, Isolation, Criticism Avoidance, Selfsacrifice, Conscientiousness, and Impulsiveness. Studies have shown the adequacy of the psychometric properties of the IDCP dimensions (Abela, 2013; Carvalho \& Primi, 2015; Carvalho \& Primi, 2016; Carvalho et al., 2014; Carvalho, Oliveira Filho et al., 2014), including validity evidence based on internal structure (Classical Test Theory and Item response Theory) and based on the relation to external variables (NEOPI-R and psychiatric diagnosis), and reliability coefficients for internal consistency.

The NEO-PI-R is a self-report inventory focused on the evaluation of adult personality composed of 240 items on a Likert scale of 5 points, ranging from 1 (strongly disagree) to 5 (strongly agree), with an applying time of approximately 25 minutes. The instrument covers five dimensions of personality, Neuroticism, Extraversion, Openness, Agreeableness, and Conscientiousness; however, for this study we considered the Neuroticism and Agreeableness dimensions. The manual of the Brazilian version presents studies demonstrating evidence of validity and satisfactory reliability indices (Costa \& McCrae, 2009).

The PID-5 is a self-report inventory developed for assessing the pathological characteristics of personality contained in criterion B of personality disorders presented in the section 3 of DSM-5
(APA, 2013). It consists of 220 items that should be answered on a Likert 4-point scale, with 0 equal to "false or often false" and 3 equal to "true or often true." The PID- 5 is represented by 25 facets, grouped into five dimensions, Negative Affect, Detachment, Antagonism, Disinhibition, and Psychoticism; for this study, we used Callousness, Deceitfulness, Hostility, Impulsivity, Irresponsibility, and Manipulativeness facets. No national studies were found checking the psychometric properties of the Brazilian version, but Krueger et al. (2012) present data that indicate the suitability of the original version of the test.

\section{Procedures}

After submission and approval of the Research Ethics Committee (CAAE: 21992113.1.0000.5514), the data collection was started in a particular university of an upcountry of São Paulo. The application was done collectively, with duration of approximately 40 minutes in one session per class. According to demand and access, some applications occurred individually in private establishments. After explaining the research objectives and agreement of the participants by signing the consent form, the instruments were applied, seeking to switch the sequence of it presentation.

With the collection finished, we proceeded to perform statistical analyzes. According to the objectives of this study, in a first moment, we computed the number of factors to be kept in the exploratory factor analysis through the parallel analysis (Hayton, Allen, \& Scarpello, 2004; Watkins, 2006). For placement of the analysis, the R software version 2.15.3 was used, since it allows the procedure of parallel analysis for polychoric variables, as is the case in the present study.

In sequence, a database for the software Mplus version 6.12 was generated in order to carry out the exploratory factor analysis with polychoric variables (E-SEM), besides getting fit indices that indicate the suitability of the structure found based on this sample. It is noteworthy also that 
the adjustment in fit indices also suggests the suitability of the sample for analysis. Finally, we executed correlation analyzes between the factors extracted to the Impulsiveness dimension, the dimensions of the NEO-PI-R and the facets of PID-5.

\section{Results}

Step 1, focused on developing new items for the Impulsiveness dimension of IDCP, resulted in 430 new items related to 13 sentences listed as relevant for the dimension. The constructs extracted from the literature and highlighted as applicable to Impulsiveness dimension were Deceitfulness, Risk Taking, Irresponsibility and Impulsivity (Krueger et al., 2012); antisocial interpersonal and self-related impairment (APA, 2013); Psychopathy (Shedler \& Westen, 2004); and antisocial, hypersexuality, insincerity, and impulsivity traits (Clark, 1990).

Following the development of the new items, we set out for analysis and independent selection of the best items. The pre-selection resulted in a set of 57 items and was based on criteria such as clarity and consistency in writing, explicit pathological content and traits not well represented in the original IDCP dimension. For the selection of the final composite items, we emphasize as our priority criterion the inclusion of items that was not well represented in the original version, which generated the exclusion of 19 items. Thus, the new version of the Impulsiveness dimension to be psychometrically tested was composed of 38 items plus 6 original items, grouped into five categories created by the authors: Inconsequence ( 8 original +1 new), Irresponsibility (6 original +3 new), Risk Taking (9 original +2 new), Deceitfulness ( 9 original + 2 new), and Manipulation (6 original +0 new). Two original items did not fit any category.

In sequence, we investigated the psychometric properties of the items pool, starting from the parallel analysis for polychoric variables, determining the maximum number of factors for the reviewed scale. We obtained four factors as maximum, with significant eigenvalues not randomly established and proceeded to the exploratory factor analysis with fit indices (E-SEM), forcing solutions of two to four factors using the Geomin oblique rotation and extraction method Maximum Likelihood Robust (MLR), considered as a robust method suitable for polychoric variables.

We evaluated the indices for the models and identified the six and five factors as the best fits models, respectively. The focus was given to these models and the factors interpretability was verified. The model with three factors showed the best interpretability, since the four-factor solution was not interpretable at all. The other solutions showed poor fit indices. Based on this, we chose the solution composed of three factors. The fit index obtained were X2/df $=2.54$ (acceptable); RMSEA = .08 (acceptable); CFI $=.57$ (unsatisfactory); and SMR $=.07$ (good), based on Hooper, Coughlan, and Mullen (2008) for index criterion. Table 1 shows the factors loadings, the number of items held by factor, and internal consistency (Cronbach's $\alpha$ ). The items that remained in each of the factors are bolded. 
Table 1

Exploratory factor analysis and internal consistency for the Impulsiveness dimension

\begin{tabular}{lccc}
\hline \multicolumn{1}{c}{ Items } & Inconsequence & Risk Taking & Deceitfulness \\
\hline B117 & $\mathbf{0 . 5 1}$ & 0.43 & 0.35 \\
I643 & $\mathbf{0 . 7 4}$ & 0.33 & 0.25 \\
I644 & $\mathbf{0 . 7 4}$ & 0.25 & 0.31 \\
I645 & $\mathbf{0 . 6 2}$ & 0.31 & 0.17 \\
I648 & $\mathbf{0 . 5 5}$ & 0.31 & 0.27 \\
I650 & $\mathbf{0 . 5 5}$ & 0.35 & 0.24 \\
I658 & 0.36 & $\mathbf{0 . 8 3}$ & 0.27 \\
I659 & 0.30 & $\mathbf{0 . 7 9}$ & 0.36 \\
I660 & 0.35 & $\mathbf{0 . 6 7}$ & 0.28 \\
I662 & 0.56 & $\mathbf{0 . 6 7}$ & 0.60 \\
I663 & 0.45 & $\mathbf{0 . 6 1}$ & 0.33 \\
I664 & 0.53 & $\mathbf{0 . 6 7}$ & 0.44 \\
I670 & 0.29 & 0.32 & $\mathbf{0 . 5 0}$ \\
I671 & 0.33 & 0.39 & $\mathbf{0 . 6 6}$ \\
I672 & 0.29 & 0.34 & $\mathbf{0 . 6 3}$ \\
I674 & 0.24 & 0.32 & $\mathbf{0 . 4 8}$ \\
I676 & 0.31 & 0.26 & $\mathbf{0 . 6 4}$ \\
I679 & 0.28 & 0.13 & $\mathbf{0 . 5 1}$ \\
Initial N items & 12 & 9 & 19 \\
Final N items & 6 & 6 & 6 \\
Initial alpha & 0.83 & 0.85 & 0.86 \\
Final alpha & 0.80 & 0.87 & 0.78 \\
\hline & & &
\end{tabular}

The final version of the Impulsivity dimension is composed of eighteen items, seventeen new, distributed into three factors with six items each. Decisively, we sought to explicitly maintain a minimum number of items per factor, since the IDCP is composed of 12 dimensions and the test administration would be extensive and exhaustive to patients with clinical issues. Therefore, we discarded some items with suitable properties. In short, we used four criteria for exclusion of items, (a) the item prejudices or not favors the internal consistency of the factor, (b) little interpretative consistency to keep the item, (c) significant loads on more than one factor (difference less than .50 in intra-factors loadings), and (d) content redundancy among items in the same factor. It is important to note that, considering the actual structure of the dimension, the proposal is that the revised dimension has its original name changed to Inconsequence, reflecting in a more appropriate way the traits it covered. In this case, the first factor should also have its name changed to Impulsivity. Henceforward in this paper, the dimension will be referred as Inconsequence and its first factor as Impulsiveness.

Internal consistency (Cronbach's $\alpha$ ) was higher than .70 in all factors, including the increase of the coefficient after excluding some items. The coefficient for the total score was .89. After defining the internal structure of the instrument, we conducted analyses to correlate the factors and total score with the dimensions and facets of the NEO-PI-R and PID-5. Table 2 shows the results of the correlations between the factors and the total score of the new Inconsequence dimension and both dimensions of the NEO-PI$\mathrm{R}$.

\section{Table 2}

Correlations between factors and total score of the new Inconsequence dimension and NEO-PI-R dimensions

\begin{tabular}{|c|c|c|c|c|c|c|}
\hline & 1 & 2 & 3 & 4 & 5 & 6 \\
\hline \multicolumn{7}{|l|}{1 Impulsiveness } \\
\hline 2 Risk Taking & $0.54^{* *}$ & & & & & \\
\hline 3 Deceitfulness & $0.46^{* *}$ & $0.49^{* *}$ & & & & \\
\hline 4 Inconsequence New Total Score & $0.84^{* *}$ & $0.85^{* *}$ & $0.74^{* *}$ & & & \\
\hline 5 Impulsiveness Original Total Score & $0.56^{* *}$ & $0.56^{* *}$ & $0.60^{* *}$ & $0.69^{* *}$ & & \\
\hline 6 Neuroticism & $0.36^{* *}$ & $0.16^{*}$ & $0.27^{* *}$ & $0.33^{* *}$ & $0.28^{* *}$ & \\
\hline 7 Agreeableness & $-0.33^{* *}$ & ${ }^{*}-0.24^{* *}$ & $-0.45^{* *}$ & $-0.40^{* *}$ & $-0.36^{* *}$ & $-0.53^{* z}$ \\
\hline
\end{tabular}

The correlations between factors of the revised dimension varied from .46 to .54 , and between factors and the new total score from .74 to .84 . Regarding Neuroticism, the correlations were all positive and greater with Impulsiveness. The correlations found for Agreeableness, unlike the correlations with Neuroticism, were all negative, and the greater correlation was with Deceitfulness. The total score for the original dimension was also calculated, and the magnitudes of correlation were similar compared to total score revised. In sequence, Table 3 shows the correlations with the facets of Neuroticism and Agreeableness. 
Table 3

Correlations between Inconsequence dimension and NEO-PI-R and PID-5

\begin{tabular}{|c|c|c|c|c|c|c|}
\hline & Factors and total score & Impulsiveness & $\begin{array}{c}\text { Risk } \\
\text { Taking }\end{array}$ & Deceiffulness & NTS & OTS \\
\hline \multirow{6}{*}{ 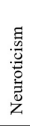 } & Anxiety & $0.24^{*+}$ & $0.16^{*}$ & $0.14^{*}$ & $0.23^{+*}$ & 0.13 \\
\hline & Anger/Hostility & $0.20^{* *}$ & 0.09 & $0.21^{* *}$ & $0.20^{* *}$ & $0.17^{* *}$ \\
\hline & Depression & $0.31^{* *}$ & $0.17^{* *}$ & $0.25^{* *}$ & $0.30^{* *}$ & $0.26^{* *}$ \\
\hline & Embarrassment/Constraint & 0.12 & 0.07 & $0.19^{*+}$ & $0.15^{*}$ & $0.14^{*}$ \\
\hline & Impulsivity & $0.52^{4+}$ & $0.31^{+*}$ & $0.26^{*+}$ & $0.47^{*+}$ & $0.43^{*+}$ \\
\hline & Vulnerability & $0.27^{* *}$ & -0.04 & $0.16^{*}$ & $0.16^{*}$ & 0.12 \\
\hline \multirow{6}{*}{ 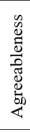 } & Trust & $-0.21^{* *}$ & $-0.14^{*}$ & $-0.32^{* *}$ & $-0.25^{* *}$ & $-0.29^{* *}$ \\
\hline & Frankness & $-0.38^{* *}$ & $-0.33^{* *}$ & $-0.45^{* *}$ & $-0.47^{* *}$ & $-0.32^{* *}$ \\
\hline & Altruism & -0.12 & -0.08 & $-0.23^{* *}$ & $-0.16^{*}$ & $-0.14^{s}$ \\
\hline & Complacency & $-0.36^{* *}$ & $-0.22^{* *}$ & $-0.32^{* *}$ & $-0.36^{* *}$ & $-0.38^{* *}$ \\
\hline & Modesty & -0.11 & -0.12 & $-0.19^{* *}$ & $-0.16^{*}$ & -0.08 \\
\hline & Sensitivity & -0.12 & -0.05 & $-0.24^{* *}$ & $-0.15^{*}$ & $-0.16^{*}$ \\
\hline \multirow{6}{*}{ 忿 } & Callousness & $0.31^{13}$ & $0.35^{* *}$ & $0.40^{* *}$ & $0.43^{* *}$ & $0.31^{* *}$ \\
\hline & Deceitfulness & $0.48^{* *}$ & $0.38^{++}$ & $0.64^{*+}$ & $0.60^{+*}$ & $0.55^{* *}$ \\
\hline & Hostility & $0.40^{* *}$ & $0.28^{* *}$ & $0.30^{* *}$ & $0.40^{* *}$ & $0.31^{* *}$ \\
\hline & Impulsivity & $0.63^{* * 4}$ & $0.39^{* *}$ & $0.31^{* *}$ & $0.56^{* *}$ & $0.44^{* *}$ \\
\hline & Irresponsibility & $0.43^{* 4}$ & $0.26^{+*}$ & $0.26^{*+}$ & $0.39^{+*}$ & $0.43^{* *}$ \\
\hline & Manipulativeness & $0.48^{* 4}$ & $0.52^{++}$ & $0.69^{4+}$ & $0.67^{+4}$ & $0.53^{* *}$ \\
\hline
\end{tabular}

In a broad perspective, the correlation between facets of Neuroticism and Agreeableness from NEO-PI-R with Impulsivity factors tended to be lower than the correlations with the facets of PID-5. Beside this, it appears that the total scores of the scale of IDCP, original and revised, were similar in most cases. Specifically regarding the facets of Neuroticism, the highest correlations were with Impulsivity, followed by Depression, in all cases. Regarding Agreeableness, the highest correlations were with Frankness and Complacency, and specifically with Trust for Deceitfulness. Related to PID-5, Callousness was similarly related to Inconsequence factors; Deceitfulness with the IDCP factor with equal name; Hostility, Impulsivity, and Irresponsibility more related to Impulsiveness; and Manipulativeness more related to Deceitfulness. Still, the new total score presented highest correlations with Impulsivity (positive, Neuroticism), Frankness (negative, Agreeableness), and Manipulativeness plus Deceitfulness (positive, PID-5).

\section{Discussion}

In the first stage of the review, the items were grouped in five categories, resembling the literature (APA, 2013; Krueger et al., 2012) Inconsequence (reckless behavior with himself and others), Irresponsibility (uncommitted style),
Risk Taking (tendency to accept and promote dangerous behavior), Deceitfulness (tendency to deceive and lie to other people), and Manipulation (manipulative behavior and style to achieve own goals). The selection of new items to be empirically tested was reviewed by judges (i.e., authors of this work), regarding the content, redundancy, and appropriateness of writing, which was aimed to improve the dimension with the inclusion of new items, replicating previous studies (Carvalho, de Souza et al., 2014; Carvalho, Sette et al., 2014).

Thirty-eight items were selected and applied to be psychometrically analyzed. As the threefactor solution was the most appropriate model, we moved on to selecting the best items, which resulted in 18 items composing the revised dimension. We observed similarity between the original total score and the new total score in the correlations with other tests, demonstrating that both reach comparable levels in the construct, focused on pathological manifestation; however, the inclusion of nine new psychometrically-selected items increased the scope and representation of the construct in the dimension. The data found by Carvalho and Primi (2015) did not indicate need for development of more pathological items for the Impulsivity dimension, indeed, it was one of the less endorsed IDCP dimensions. Considering that the original Impulsivity was composed only by 6 items, it is reasonable to assume that with three times the number of items, more of the construct will be measured, as the correlations suggests. Based on the actual structure of the dimension, the original name of the dimension was presently proposed to change to Inconsequence, reflecting in a more appropriate way the traits covered by the dimension; and the first factor's name changed to Impulsiveness.

The Inconsequence three factors include characteristics such as (Impulsiveness) imprudence and rush in the decision-making process; risk taking, adventure and recklessness style, and danger-seeking (Risk Taking); and tendency to control people, deceive, and lie to reach own gain (Deceitfulness). The dimension coverage clearly increased, as the original 
dimension was more focused on risk taking (Carvalho \& Primi, 2015) which is important to some personality functioning, mostly, antisocial (APA, 2013; Hopwood, Thomas, Markon, Wright, \& Krueger, 2012; Samuel, Lynam, Widiger \&, Ball, 2012). Moreover, the scale had a moderate, not higher, correlation between its factors, which is an important indicator of the possibility of Inconsequence profiles, which should be investigated in future studies.

Regarding the psychometric quality of the new dimension, we observed adequate internal consistency coefficients (Cronbach's $\alpha$ ) for the total score and three factors (Embretson, 1996; Nunnally, 1978), including cutoff for clinical assessment (American Psychological Association, American Educational Research Association, \& National Council on Measurement in Education, 2014). Besides, the correlation pattern between Inconsequence factors set out the possibility of profiles establishment. For instance, two patients may show high scores in the Inconsequence dimension, but one of them presents high scores only in Impulsiveness and Risk Taking and the other in Risk Taking and Deceitfulness. The first is likely to exhibit reckless behavior towards others and himself, including dangerous behavior; the latter, despite also showing dangerous behavior, probably would demonstrate manipulative behaviors, such as lies and seduction. Moreover, the correlations of the factors were greater with the new total score in comparison to the original, suggesting that the construct coverage has been increased.

Relative to correlation with NEO-PI-R dimensions (Costa \& McCrae, 2009), an important issue is the absence of dimensions and facets corresponding to the content considered encompassed by the Inconsequence dimension, which reduces the possibility of high magnitudes (r) of correlation. Moreover, unlike IDCP and PID-5, the NEO-PI-R dimensions were developed for evaluation of healthy personality traits (despite Neuroticism, that encompasses less adaptive ways, but was not designed to direct assess pathological levels of the constructs), which should also have an impact on the magnitude of the correlations. Specifically related to Neuroticism and Agreeableness dimensions, all the correlations were positive and negative (mainly with Deceitfulness), respectively, which is conceptually coherent since Neuroticism is related to maladaptive functioning and Agreeableness to care and concern about others' feelings and wishes (Costa \& McCrae, 2009). As expected (Carvalho \& Primi, 2015), these data suggest that the Inconsequence dimension is more related to imprudent and reckless style with manipulative behavior.

Among the Neuroticism facets, the highest correlations were with Impulsivity, which is very consistent, considering that this facet assesses risk taking behavior and imprudent thought process to decision making (Costa \& McCrae, 2009), like the IDCP reviewed dimension, Agreeableness facets also showed an interesting correlation pattern, as Frankness and Complacency presenting highest negative magnitudes, indicating that the Inconsequence factors are related to lying, manipulating, and not being submissive to others. Moreover, Trust was correlated to Deceitfulness, suggesting that the IDCP factor is related to deceive others.

In contrast, the correlations between Inconsequence factors and PID-5 facets were more expressive, which should be related to the point that these instruments also target to pathological levels, as IDCP. We observed that all Inconsequence factors correlated similarly with Callousness, indicating that the IDCP dimension is related to not being sensitive to others' feelings and wishes, which is consistent with the latent construct of the IDCP dimension (Carvalho \& Primi, 2015), especially considering the relationship of the dimension with antisocial functioning (APA, 2013). Deceitful from PID-5 correlated mainly with the factor with the same name, more than that, both are related to tendency in lying and deceive people (Krueger et al., 2012), which explains the correlation. Hostility was more correlated to Inconsequence, probably because this IDCP factor measured the lack of respected with others, even harming people around, which is typical 
in the antisocial style (APA, 2013), and refers to Hostility PID-5 dimension (Krueger et al., 2012). Likewise, Impulsivity and Irresponsibility from PID-5 showed highest correlations also with IDCP's Impulsiveness, suggesting that this factor is related to imprudent and unwise behavior, with lack of wariness to decision making, which is expected for the Inconsequence dimension (Carvalho \& Primi, 2015). As consistent as these results, the correlation between Manipulativeness and Deceitfulness suggests that the IDCP factor is mainly related to a tendency in lying and deceiving people (Krueger et al., 2012).

The data presented suggest evidence validity to the reviewed dimension. Considering the definition of Carvalho and Primi (2015) of the original Impulsivity dimension, the present data make clear that the reviewed dimension is more related to antisocial functioning (APA, 2013; Anderson et al., 2014; Coid \& Ulrich, 2010), as the factors assess deceitfulness, irresponsibility, manipulativeness behavior, and risk taking. Future studies must look for the IDCP dimension more related to borderline functioning and, also, if some of the Inconsequence factor is related to this personality style.

We emphasize the importance of replication of the structure found in future research, and of the verification of the reliability indexes based on the levels of the participants in the latent construct, for example, using local reliability (Daniel, 1999). As a limitation of the study we highlight the characteristic of the sample, not including clinical group. Extending of investigations in clinical groups, with primacy of patients with personality disorders, will improve the applicability of the IDCP.

\section{Acknowledgements}

This research was founded by Fundação de Amparo à Pesquisa do Estado de São Paulo (FAPESP).

\section{References}

Abela, R. K. (2013). Validity evidences for the Inventário Dimensional Clínico da Personalidade (IDCP) in outpatient sample based on the DSM-IV-TR diagnoses of personality disorders (Unpublished master's thesis). Universidade Federal de São Paulo, SP, Brasil.

American Psychiatric Association. (2003). Diagnostic and statistical manual of mental disorders (4th. ed. rev.). Washington, DC: Author.

American Psychiatric Association. (2013). Diagnostic and statistical manual of mental disorders (5th. ed.). Washington, DC: Author.

American Psychological Association, American Educational Research Association, \& National Council on Measurement in Education. (2014). Standards for psychological and educational testing. New York: American Educational Research Association.

Anderson, J. L., Sellbom, M., Wygant, D. B., Salekin, R. T., \& Krueger, R. F. (2014). Examining the associations between DSM-5 section III antisocial personality disorder traits and psychopathy in community and university samples. Journal of Personality Disorders, 28(5), 675-697. http://dx.doi.org/10.1521/pedi_2 01428134

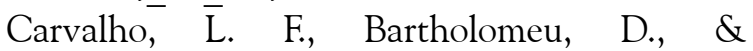
Silva, M. C. R. (2010). Instrumentos para avaliação dos transtornos da personalidade no Brasil. Avaliação Psicológica, 9(2), 289-298. Retrieved from http://pepsic.bvsalud.org/scielo.php?s cript $=$ sci_arttext $\&$ pid $=$ S1677-047120100 00200013

Carvalho, L. F., Oliveira Filho, A. Q., Pessotto, F., \& Bortolotti, S. L. V. (2014). Application of the unfolding model to the aggression dimension of the Dimensional Clinical Personality Inventory (DCPI). Revista Colombiana de Psicologia, 23(2), 
339-349. doi: https://doi.org/10.15446/ rcp.v23n2.41428

Carvalho, L. F., \& Primi, R. (2015). Development and internal structure investigation of the Dimensional Clinical Personality Inventory. Psicologia: Reflexão e Crítica, 28(2), 322-330. doi: http:// doi.org/10.1590/1678-7153.201528212.

Carvalho, L. F., \& Primi, R. (2016). Prototype matching of personality disorders with the Dimensional Clinical Personality Inventory. Psicologia: Teoria e Pesquisa, 32 (2), 1-9. doi: http://doi.org/10.1590/0102-3772e322214

Carvalho, L. F., Primi, R., \& Stone, G. E. (2014). Psychometric properties of the Inventário Dimensional Clínico da Personalidade (IDCP) using the Rating Scale Model. Avances en Psicologia Latinoamericana, 32(3), 433-446. doi: http://doi.org/10.12804/apl32.03.2014.09

Carvalho, L. F., Sette, C. P., Capitão, C. G., \& Primi, R. (2014). Propriedades psicométricas da versão revisada da dimensão necessidade de atenção do Inventário Dimensional Clínico da Personalidade [Psychometric properties of the revised attention seeking dimension of the Dimensional Clinical Personality Inventory]. Temas em Psicologia, 22(1), 147-160. http://dx.doi.org/10.9788/TP201 4.1-12

Carvalho, L. F., Souza, B. D. B., \& Primi, R. (2014). Psychometric properties of the revised conscientiousness dimension of Inventário Dimensional Clínico da Personalidade (IDCP). Trends in Psychiatry and Psychotherapy, 36(1), 23-31. http://dx.d oi.org/10.1590/2237-6089-2013-0024

Clark, L. A. (1990). Toward a consensual set of symptom clusters for assessment of personality disorder. In J. N. Butcher \& C. D. Spielberger (Orgs.), Advances in personality assessment (pp. 243-266). New Jersey: Erlbaum.

Coid, J., \& Ulrich, S. (2010). Antisocial personality disorder is on a continuum with psychopathy. Comprehensive Psychiatry,
51 (4), 426-433. http://dx.doi.org/10.1016/j .comppsych.2009.09.006

Costa, P. T., Jr., \& McCrae, R. (2009). NEOPI-R - Inventário de Personalidade NEO Revisado - Manual [NEO-PI-R - Revised NEO Personality Inventory - Manual]. São Paulo: Vetor.

Daniel, M. H. (1999). Behind the scenes: Using new measurement methods on the DAS and KAIT. In S. E. Embretson \& S. L. Hershberger (Orgs.), The new rules of measurement: What every psychologist and educator should know (pp. 37-63). New Jersey: Erlbaum.

Embretson, S. E. (1996). The new rules of measurement. Psychological Assessment, 8(4), 341-349. http://dx.doi.org/10.1037/1 040-3590.8.4.341

Guy, L. S., Poythress, N. G., Douglas, K. S., Skeem, J. L., \& Edens, J. F. (2008). Correspondence between selfreport and interview-based assessments of antisocial personality disorder. Psychological Assessment, 20(1), 47-54. http://dx.doi.org/ 10.1037/1040-3590.20.1.47

Hayton, J. C., Allen, D. G., \& Scarpello, V. (2004). Factor retention decisions in exploratory factor analysis: A tutorial on parallel analysis. Organizational Research Methods, 7(2), 191-205. http://dx.doi.org/1 0.1177/1094428104263675

Hooper, D., Coughlan, J., \& Mullen, M. R. (2008). Structural equation modelling: Guidelines for determining model fit. The Electronic Journal of Business Research Methods, 6(1), 53-60. Retrieved from https://www.researchgate.net/publica tion/254742561 Structural Equation Mo deling_Guidelines_for_Determining_Mod el_Fit

Hopwood, C. J., Thomas, K. M., Markon, K. E., Wright, A. G. C., \& Krueger, R. F. (2012). DSM-5 Personality traits and DSMIV personality disorders. Journal of abnormal psychology, 121 (2), 424-432. doi: 10.1037/ a0026656

Huang, Y., Kotov, R., de Girolamo, G., Preti, A., Angermeyer, M., Benjet, C., . . . Kessler, R. 
C. (2009). DSM-IV personality disorders in the WHO World Mental Health Surveys. British Journal of Psychiatry, 195, 46-53. htt p://dx.doi.org/10.1192/bjp.bp.108.058552

Krueger, R. F., Derringer, J., Markon, K. E., Watson, D., \& Skodol, A. E. (2012). Initial construction of a maladaptive personality trait model and inventory for DSM-5. Psychological Medicine, 42(9), 1879-1890. http://dx.doi.org/10.1017/S003 3291711002674

Lenzenweger, M. F., Lane, M. C., Loranger, A. W., \& Kessler, R. C. (2007). DSMIV personality disorders in the National Comorbidity Survey Replication. Biological Psychiatry, 62, 553-564. http://dx.doi.org/10 $.1016 /$ j.biopsych.2006.09.019

McCloskey, M. S., New, A. S., Siever, L. J., Goodman, M., Koenigsberg, H. W., Flory, J. D., \& Coccaro, E. F. (2009). Evaluation of behavioral impulsivity and aggression tasks as endophenotypes for borderline personality disorder. Journal of Psychiatric Research, 43(12), 1036-1048. http://dx.doi. org/10.1016/j.jpsychires.2009.01.002

Millon, T., \& Grossman, S. (2007a). Moderating severe personality disorders. New Jersey: Wiley.

Millon, T., \& Grossman, S. (2007b). Overcoming resistant personality disorders. New Jersey: Wiley.

Millon, T., Grossman, S., \& Tringone, R. (2010). The Millon Personality Spectrometer: A tool for personality spectrum analyses, diagnoses, and treatments. In T. Millon, R. F. Krueger \& E. Simonsen (Orgs.), Contemporary directions in psychopathology: Scientific foundations of the DSM-V and ICD-11 (pp. 391-418). New York: Guilford.

Moeller, F. G., Barratt, E. S., Dougherty, D. M., Schmitz, J. M., \& Swann, A. C. (2001). Psychiatric aspects of impulsivity. American Journal of Psychiatry, 158, 1783-1793. http:/ /dx.doi.org/10.1176/appi.ajp.158.11.1783

Nunnally, J. C. (1978). Psychometric Theory. Mcgraw-Hill: NewYork.

Ohayon, M. M. (2009). Impulsivity, aggression and personality. Journal of Psychiatric
Research, 43, 1005-1006. http://dx.doi.org/ 10.1016/j.jpsychires.2009.07.003

Poythress, N. G., \& Hall, J. R. (2011). Psychopathy and impulsivity reconsidered. Aggression and Violent Behavior, 16(2), 120-134. http://dx.doi.org/10.1016/j.avb.2 011.02 .003

Samuel, D. B., Lynam, D. R., Widiger, T. A., \& Ball, S. A. (2012). An expert consensus approach to relating the proposed DSM-5 types and traits. Personality Disorders: Theory, Research, and Treatment, 3(1), 1-16. http://dx.doi.org/10.1037/a0023787

Shedler, J., \& Westen, D. (2004). Dimensions of personality pathology: An alternative to the five factor model. American Journal of Psychiatry, 161 (10), 1743-1754. http://dx.d oi.org/10.1176/appi.ajp.161.10.1743

Swann, A. C., Lijffijt, M., Lane, S. D., Steinberg, J. L., \& Moeller, F. G. (2009). Trait impulsivity and response inhibition in antisocial personality disorder. Journal of Psychiatric Research, 43(12), 1057-1063. http://dx.doi.org/10.1016/j.jpsy chires.2009.03.003

Watkins, M. W. (2006). Determining parallel analysis criteria. Journal of Modern Applied Statistical Methods, 5(2), 344-346. http://dx .doi.org/10.22237/jmasm/1162354020

\section{Notes}

* Research article. 